Gerd Grözinger, Marlene Langholz-Kaiser, Doreen Richter*

\title{
Regional Innovation and Diversity: Effects of Cultural Diversity, Milieu Affiliation and Qualification Levels on Regional Patent Outputs**
}

This paper explores the relationship between regional labour market characteristics and innovation outcomes in the Federal Republic of Germany. In particular, we use regressions to determine how the composition of the regional population - in terms of their human capital endowments, their cultural diversity and their milieu affiliation - influences patent activities. We also test different spatial units in our models to establish which regional level is more appropriate for our analysis.

Key words: regions, innovation, patents, milieus, diversity (JEL: O31, R10, R19)

\section{Introduction}

Regions are complex constructs with internal linkages and cooperative relationships that create unique conditions for successful business activities. Since firms do not create innovations isolated from their environment, it is important to consider regional conditions that influence the choice of options available at the individual and at the firm level. Therefore, regional analysis is of high relevance for researchers as well as for political actors (Grözinger \& Matiaske, 2010). Regional innovation capability is a concept that emerges from the interplay of actors located within the region and providing for the structure of regional competitiveness.

Whilst the importance of human capital for economic development is widely agreed upon in growth economics (Lucas, 1988; Mankiw, Romer, \& Weil, 1992), other dimensions have received less attention. As a result, our research deals with additional regional labour market characteristics and their influence on the innovation output of regions. Empirical studies on the relationship between cultural diversity and innovation remain scarce, but are increasingly becoming relevant due to the demographic developments in industrial nations. Our first research question reflects on the effect of cultural diversity on the innovation output in German regions. Our

* Prof. Dr. Gerd Grözinger, Europa-Universität Flensburg, Auf dem Campus 1, 24943 Flensburg, Germany. Email: groezing@uni-flensburg.de.

Marlene Langholz-Kaiser (M.A./M.Sc.), Europa-Universität Flensburg, Auf dem Campus 1, 24943 Flensburg, Germany. Email: marlene.langholz-kaiser@uni-flensburg.de.

Doreen Richter, TWT GmbH Science \& Innovation, Oskar-Schlemmer-Straße 11, 80807 München, Germany. Email: doreen.richter@twt-gmbh.de.

** Article received: June 17, 2015

Revised version accepted after double blind review: February 13, 2017

mrev, 28 (2) 2017, $149-174$ 
findings clearly depict a positive effect and thereby confirm the results of previous research conducted on the topic.

Meanwhile, the relationship between social milieus and innovation has not been analysed till date. Our second research question, whether the dominance of certain milieu affiliations in regions has a positive effect on the innovation output, thereby represents a novel approach, linking the ability to innovate to mentalities prevailing among certain groups. We find that the capability to innovate does indeed vary among different milieu groups and that there is a relationship between the lack of these groups in certain regions and a low level of innovation output. Thirdly, we apply our models to different spatial levels in order to determine the most suitable aggregate for answering our research questions.

The paper thus contributes to existing research on regional innovativeness and seeks to further investigate the link between the ability to innovate and mentalities that are dominant among certain groups.

In the following chapters, we will first provide the theoretical underpinnings of regional innovativeness, diversity and milieu affiliation and derive our hypotheses (2.1-2.4). This is followed by a discussion on the measurement of regional patent activities (2.5), including the use of different indicators and different spatial units for the analysis. In section 3, we use regression models to test our initial assumptions; in particular, we compare the effects that our indicators have on (i) the patent output; (ii) at the level of administrative districts ("Kreise"); and (iii) at the level of spatial planning regions ("Raumordnungsregionen"). The conclusion of the paper is provided in Section 4.

\section{Theoretical Framework}

\section{Regions and Regional Innovation Systems}

Empirical evidence from innovation research demonstrates that local and regional factors play an important role for organizational innovation processes. According to Acs, Anselin, and Varga (2002), the production of new scientific and technological knowledge has the tendency to concentrate spatially. The most important reason for this appears to be rooted in the transfer modes of knowledge. Acs et al. (2002) underline that the most recent and therefore most valuable knowledge can only be found in a complex, undefined and uncoded format, making it transferable only through personal contact. Therefore, the close proximity on a local or regional level is vital for the development of innovations.

The productivity of enterprises does not only depend on its own expenditures on research and development (R\&D), but also on the spending of other companies and industries. (Jaffe, Trajtenberg, \& Henderson,1992). In light of this, innovations are not an isolated performance of individual organizations, but dependent on regional contextual factors such as the available labor force, access to networks and 
potential cooperation's as well as knowledge spillovers and the successful transfer of new knowledge (Arnold, Mattes, \& Sander, 2014).

But the particular difficulty in regional analysis is to define the regional context or layout in which those phenomena occur, and to make them measurable. Quoting Sinz "a region is considered as a coherent subspace of medium size in a total space, which is demarcated due to certain characteristics. In everyday language, the term 'region' or the attribute 'regional' is usually used when conditions or processes are to be referred to, which affect more than the local context, but are located below the state level" (Sinz, 2005, p. 919, own translation). Bathelt and Glückler (2012) describe a region as "a concrete segment of the earth's surface, which is distinguishable due to certain principles or structures and thus can be differentiated from other regions" (p. 75, own translation).

In addition to this focus on the intermediate function of regions, according to Miggelbrink (2002), regions can be set in a state-centered relationship to the nation state and be ranked hierarchically in perception as a social and political-administrative organization: local - regional - national - supranational - global (Miggelbrink, 2002). However Miggelbrink (2002) also points out that such definitions fall short. Regions must be defined not only as a specific spatial unit at an intermediate level, but form a fixed space based on attribution of social interaction and cohesion.

Accordingly, Cooke (2001) describes a region as a political entity at the meso-level, which is located between the national and local government level, has a cultural or historical homogeneity and holds certain legal powers which enable it to have an influence on the economic development of the region (Cooke, 2001). For the purpose of this paper $^{1}$ the term economic development includes the ability to innovate.

In economics, the possibility of common action (an increase in regional economic growth, regional innovation capability) is attributed to regions. Assuming this, various theoretical concepts as well as functionally oriented approaches to the formation of economic regions emerged. Important inputs have been provided by economic geographers like von Thünen (1826), Marshall (1890), Weber (1909), Hotelling (1929), Ohlin (1933), Christaller (1933), Lösch (1940), Isard (1979) and more (see Karlsson, 2008).

In the $1990 \mathrm{~s}$, spatial concentrations have been applied again in the economics debate by authors such as Krugman (1997), Porter (1998), Fujita, Venables, and Mori (2001) and won back attention in many areas of the economy (city economy, location theory and international trade theory) (Karlsson, 2008, p. 1-2).

1 The paper is based on the results of a joint research project between the European-University of Flensburg, the University of Hamburg and the Helmut-Schmidt-University Hamburg with the title "Innografie: Innovation and demographic change" that was conducted 2012 and 2015. The project was financed by the Germany Ministry for Education and Research (BMBF, Förderkennzeichen 01HH11029). 
This research resulted in different approaches of urban and regional economics, such as in the theory of National Innovation Systems (NIS) (Freeman, 1987), of endogenous growth (Lucas, 1988; Romer, 1990), in the cluster and network concept (especially Porter, 1998), in the new economic geography (Krugman, 1997), of the Regional Innovation Systems (RIS) (Cooke, 2001) or the theory of the Creative Class (Florida, 2004, 2008).

Starting from the Anglo-Saxon and Scandinavian countries, the approach of the RIS has grown since the beginning of 1990 as a new research paradigm (Rehfeld \& Terstriep, 2013). RIS are characterized by joint innovation activities of enterprises and the creation and dissemination of knowledge through regionally based organizations, such as universities, training institutions, research institutes and technology transfer agencies and provide an analytical framework to better understand innovation processes and structures in regional cooperation (Bellmann, Crimmann, Evers, \& Hujer, 2013). Thus, one can understand RIS as the "total of organizations and institutions that are involved in the creation, dissemination and application of scientific and technological knowledge [...]", (Arnold et al., 2014, p. 79). They form a multi-dimensional interactive structure between the central groups of actors in the region, which interact within various networks and with each other (Arnold et al., 2014). This networking and the related exchange of human capital and knowledge influences the innovation performance of local companies to a large degree.

However, the complexity and diverse dynamics in the network and innovation systems makes it difficult to apply the RIS concept to quantitative analyses. It is possible, however, to measure innovation activities using a number of indicators available at different spatial levels. Sorted according to size and in descending order, in the Federal Republic of Germany these are:

\section{- Raster Data}

- Postcode areas (approx. 8,000)

- Districts and district-free cities (402)

- Labor market regions (depending on the concept 140-270)

- Planning regions (96)

- States (16)

- National state

As there is not sufficient data available for the first two categories, we will not use raster data and/or postcode areas. Labor market regions incorporate commuter traffic as a basis for their calculation, yet, they will also not be considered in this paper due to the considerable effort involved in the data collection and aggregation. Another problem exist in respect to the last two dimensions. The usefulness of calculations for regional innovation performance at the state-level is limited, since the spatial layout at the state or even nation-state level is too large and generally encom- 
passes several different economic regions. Predictions would therefore be rather imprecise and region-specific recommendations impossible to derive. The nation state level is mainly suitable for international comparisons, which can only fulfill the function of a comparative benchmark for regional innovation performance in our study.

Consequently, we will focus on data available at the district and the spatial planning level for our calculations.

\section{Regional Cultural Diversity and Innovation Capability}

Innovation scholars from different disciplines have argued that differences in technological capabilities can be explained satisfactorily only when cultural factors are taken into account (Franke, Hofstede, \& Bond, 1991; Landes, 1998; Harrisson \& Huntington, 2000). More specifically, there is ample evidence for differences in innovation culture across countries. The term innovation culture refers to the institutions (norms, values formal and informal) that significantly influence how the actors involved in an innovation process perceive economic and technical challenges, providing them with strategies to tackle these (Wieland, 2006; Didero, Gareis, Marques, \& Ratzke, 2008). The underlying assumption is that a certain degree of homogeneity exists within nation states and that their members share a certain set of cultural taxonomies (most influential Hofstede, 1980).

Several studies (Barnett, 1953; Hofstede, 1980; Rothwell \& Wissema, 1986; Beteille, 1977; Mokyr, 1991; Herbig \& Miller, 1993; Lee, 1998; Taylor \& Wilson, 2012) assign higher innovation capabilities to societies which are characterized by:

- Higher individualism

- Willingness to take risks

- Readiness to accept change

- Long-term orientation

- Low on power/status/hierarchy (low power distance)

- Weak uncertainty avoidance

- Openness to new information

- Frequent travel

- Positive attitude towards science

- High education levels

- Early adopters

- Religion (however, depending on which religion)

Empirical research on the relationship between cultural factors and innovation has found that culture matters not only for the national level, but also for innovation 
rates at the organizational and the individual level (for an overview, see Kirkman, Lowe, \& Gibson, 2006).

Advocates of diversity argue that a (cultural) diverse staff can draw from a high variety of resources leading to a higher degree of flexibility, creativity and problem-solving mechanisms. At a very general level, diversity can thus have positive effects on innovation and on the productivity of firms.

Yet, the assumption that diversity is always positive cannot be confirmed by existing research. Research on the relationship between diversity and organizational performance is inconclusive and scholars highlight that contextual factors are important when trying to make use of the potential possessed by diverse groups. Negative effects of diversity and resulting costs can result from communication barriers between people of different linguistic backgrounds and cultures. U.S. studies, for example, show that a limited exchange between different cultural groups was more likely to lead to productivity losses.

Studies that analyze the effects of cultural diversity at a regional level primarily focus on the correlation between diversity and economic growth, e.g. productivity in US regions (Ottaviano \& Peri, 2006; Bellini, Ottaviano, Pinelli, \& Prarolo, 2013; Alesina \& La Ferrara, 2005). The relationship between cultural diversity and innovation has so far only been the focus of very little research (Stuen, Mobarak, \& Maskus, 2012; Kerr \& Lincoln, 2010; Hunt, 2011; Taylor \& Wilson, 2012), this is especially true for studies that focus on spatial units below the country level.

Stuen et al. (2012) and Kerr and Lincoln (2010) were able to show that highly skilled immigration leads to an increase of US American patent activities. In the German context, Niebuhr (2006) demonstrated that cultural diversity (measured by nationality), especially among high-skilled persons, can increase the performance of regional production processes in $\mathrm{R} \& \mathrm{D}$ sectors, and thus patent activities. She also finds a particularly strong influence in the field of high-skilled migration.

Diversity (in its different forms) is viewed as a key asset of modern cities and a driver of urban development (e.g., Florida 2004, 2006). Several authors point to the complimentary nature of the skills of immigrant and native workers. In that sense, different cultural groups would offer different services (Ottaviano \& Peri, 2005), work in research-related career fields more likely than the average (Kerr and Lincoln, 2010), or graduate in engineering and the natural sciences more frequently (Hunt \& Gauthier-Loiselle, 2009; Wadhwa, Gereffi, Rissing, \& Ong, 2007). Richard Florida argues that a diverse urban environment attracts people from knowledge-intensive industries and thus enhances the creative capital of cities (Florida, 2004).

Another argument points out that regional $\mathrm{R} \& \mathrm{D}$ expenditure of long-established companies creates local knowledge spillovers and non-intended knowledge. As only a portion of the newly generated knowledge can be immediately applied in the exis- 
tent economic context, a large number of business opportunities remain available for exploitation by newcomers. According to Audretsch, Dohse, and Niebuhr (2010), cultural diversity depicts a mechanism that increases the regional demand for knowledge spillovers and the likelihood of merging a newly created piece of knowledge in the region with an individual that can realize and commercially use this knowledge.

\section{Regional Age Structure and Innovation Capability}

To start with, a literature review about age and individual productivity came to the conclusion that after the age of 50 the work performance tends to decline (Skirbekk, 2003). However, the declining performance must not necessary include the capability to innovate where 'wisdom' may play a relevant role (Baltes \& Staudinger, 2000).

Gregory and Patuelli (2013) argue that the demographic changes in industrial nations are one of the major challenges in the $21^{\text {st }}$ century. It is likely that the demographic ageing will affect regional employment structures to different degrees. Regional labor market disparities could increase when some regions attract mainly young and educated employees while others lack behind. The authors show that the gap between rural and densely-populated areas is widening and that ageing and weakly innovative regions have only minor chances to reverse this trend. In particular, they find a positive correlation between a low average age, a high level of age diversity and patent activities. Calculating regional knowledge functions, Arntz and Gregory (2014) came to the conclusion that in Germany "younger workers boost regional innovations, but this effect partly hinges on the presence of older workers as younger and older workers turn out to be complements in the production of knowledge" (p. 3). It is therefore useful to have both a look at the share of employees below 50 and the age composition of the workforce.

\section{Social Milieus}

Social milieus are defined as social groups, whose members are closely related in terms of their values, everyday life aesthetics, and behavioral routines, places of residence, leisure and consumer preferences, as well as the level of education, profession and social situation. Milieu models are primarily used for social structure analysis and explanation of social inequality in the area of research as well as for target group analysis in the area of marketing.

According to Diaz-Bone (2003), a milieu "is understood as a social group, which has a high degree of uniformity in matters of life plans and lived life forms, desired pleasures, political attitudes, leisure activities and consumption as well as other aspects of daily life." (p. 365). Hradil (2006) defines social milieu as "groups of likeminded $[\ldots]$ which each demonstrate similar values, principles of life style, and relationships with people and mentalities." (p. 4). He clearly demarcates the concept of 
milieus from the terminology of social classes. Within the milieus, individuals with similar mentalities are grouped together. These common mentalities may be rooted in their occupation, religion, region, way of life, politics, moral or other contexts. Theoretical models that use the class concept, on the other hand focus on aspects that can be objectified (occupational status, income, education).

Hradil (2006) stresses the need to differentiate between milieu and lifestyle and criticizes as the synonymous use of both. He attributes more depth and durability to the former, making change of milieus difficult and a lot less frequent than a change in lifestyle, which mainly refers to private life and leisure as well as externally observable behavior routines.

\section{SINUS milieus}

In the second half of the 1970 s, Jörg Ueltzhöffer and Berthold Flaig (1980) developed a milieu approach for market and social research purposes. The Sinus-Model was built on this approach and has been used by advertising agencies, political parties, trade unions, churches and media companies specializing in strategic marketing, communication and product development. Within the model, people are grouped together according to similar outlooks on life and ways of life. This includes fundamental values as well views about work, family, leisure, money and consumption. (Sociovision, 2009; Barth \& Flaig, 2012).

As demonstrated by the following chart, socio-demographic characteristics are also incorporated into the sinus milieus. The vertical axis shows the social situation, measuring education, income and occupation, while the horizontal axis locates the different milieus according to their basic orientations. The further a milieu extends to the right, the more modern it is in its basic orientation in a socio-cultural sense. In contrast to the traditional layer models, milieus are less sharply demarcated from each other and also overlap partially (Sociovision, 2009; Barth \& Flaig, 2012). 


\section{The Sinus-Milieus ${ }^{\circledR}$ in Germany}

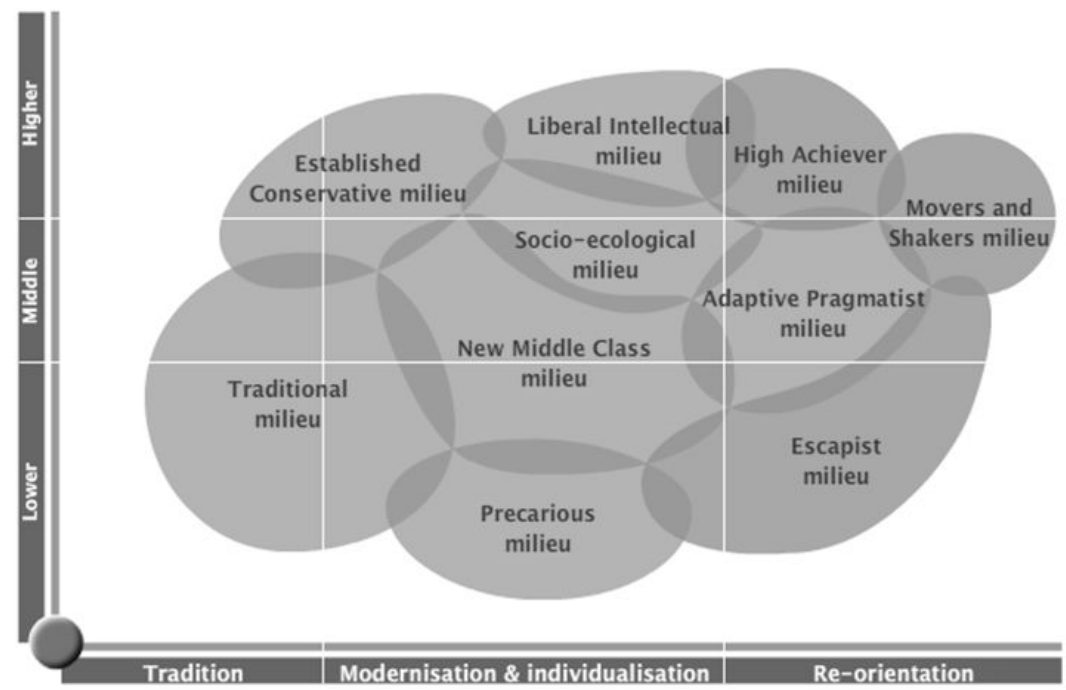

Figure 1: The SINUS Milieus in Germany 2013 (SINUS Markt- und Sozialforschung GmbH 2013)

In order to capture the basic milieu features, a combination of qualitative and quantitative interviews is applied. The data is continuously updated; therefore the Sinus Institute is able to adapt its social model to the latest socio-cultural situation (DiazBone, 2003, p. 370; SINUS Markt und Sozialforschung GmbH, 2011, p. 20).

\section{Microm Geo-Milieus}

The Micromarketing-Systems and Consult GmbH (microm) uses the Sinus-Model for the calculation of their Geo-Milieus making it possible to determine milieu affiliations on the basis of housing units across the Federal Republic of Germany.

The theoretical background is the micro-geographic marketing approach: people, who live in close proximity to each other, are similar in their social status, their lifestyle and their consumer behavior. This can relate to neighborhoods, road sections or even individual residential buildings. In practice, settlement areas are broken up into specific units and associated with socio-demographic, psychographic and behavioral oriented data.

Although innovation capability is not a concept that is familiar to the research of milieus, it is possible to link certain traits from the milieu model to it. For instance, we can expect those milieus to be more active in the field of innovation that are 
open to new ideas and willing to take risks, consequently being located more on the right side of the horizontal axis. On the other hand, its members need to possess the skills that are necessary for the generation of patents. A higher level of education should thus be of significance and the milieu therefore be located in the upper vertical.

\section{Hypotheses}

Based on our theoretical assumptions and the results of previous research, we derived the following hypothesis:

H1: We assume that the availability of highly qualified labor has a positive effect on regional innovation output.

H2: Based on the above findings, we predict that cultural diversity has a positive effect on innovation, but that this relationship is not necessarily a linear one.

H3: Thirdly, we hypothesize that there is a relationship between milieu affiliation and innovation ability on the regional level.

H4: Fourthly, we expect that the age structure of the population affects the innovation output in a way that regions with a high level of age diversity andlor a relatively high proportion of employees in the most productive age group are more innovative.

H5: Finally, we assume that there are differences in the quality of our estimates depending on the regional level that we apply. Due to their conformity with economic regions, we expect better results from the application of spatial planning regions than from calculations based on administrative districts. 
In sum, we assume the following relationships between regional characteristics and patent output:

- Age Structure

- Human Capital

- Cultural Diversity

- MilieuAffiliation

- Population Density

- Industrial Quota
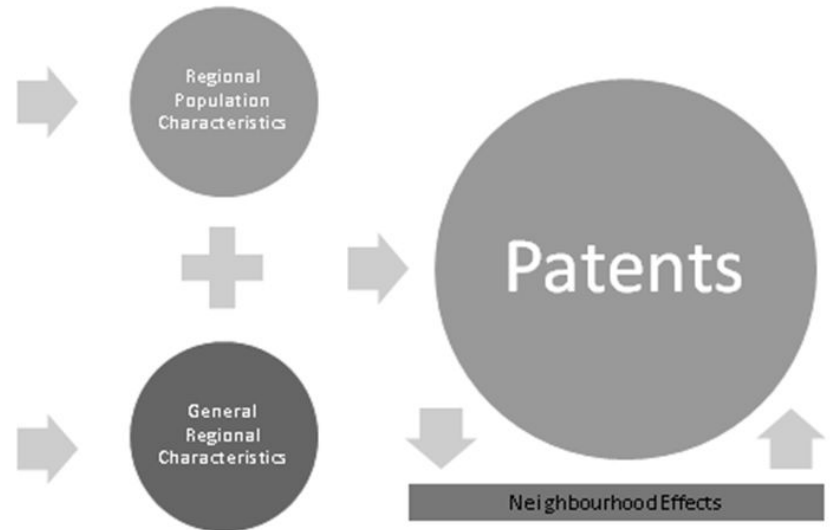

Figure 2: Relationship between regional characteristics and patents

\section{Methodology}

\section{Data Collection}

We used data available on the level of districts/district free-cities as well as on the level of planning regions. Some data was only available at the level of districts. If this was the case, we aggregated the data for planning regions from the district level.

We acknowledge that this approach limits the transferability of the results to functional economic regions, as administrative regions do not necessarily represent naturally-grown business networks. This means that at the administrative district level a correct reflection of economic correlations is not possible as it deals with historically prospered and for administrative purposes constructed units (Kosfeld \& Werner, 2012). The analysis of regional innovation capability on this level neglects the effects of economic unity, such as those that arise through commuting (Kosfeld \& Werner, 2012; Budde \& Eilers, 2014; Bellmann et al., 2013).

The planning regions form the observation and analysis framework of the federal spatial planning and are calculated on the basis of the administrative boundaries of the administrative districts and district-free cities. Therefore, a variety of official statistics is available and the calculation of figures for this administrative level is rather simple. 
In addition, planning regions are particularly suitable for social science analyzes due to a fine conformity with economic regions (Grözinger \& Matiaske, 2005).

When measuring regional innovation capability, one can distinguish between input indicators ( $\mathrm{R} \& \mathrm{D}$ personnel, R \& D expenditure, high-skilled workers), intermediate indicators (patent applications) and output indicators (entrepreneurship / business registrations, productivity growth) (Bosetti, Verdolini, \& Cattaneo, 2012).

Data that is far more robust is available for the detection of innovation inputs than for the determination of innovation outputs (Arnold et al., 2014). There are a number of sources and providers that offer spatially aggregated data to describe the innovation-related dimensions. Nonetheless, the measurement of the actual achieved innovation performance can only be approximated. For this purpose, it is common to use patent statistics for a number of pragmatic reasons (Brenner \& Brökel, 2011). For a detailed discussion of the advantages and disadvantages of patent applications, please refer to Griliches (1990), Smith (2005) and Richter, Grözinger, and Langholz (2015). We decided to use patent statistics for Germany and received the data for the year 2009 from the Association for the Promotion of German Science and Humanities.

The remaining data, with exception of the milieu information, was derived from the INKAR-CD by the BBR.

Aggregated data on milieu dispersion, we obtained from the Micromarketing-Systems and Consult $\mathrm{GmbH}$.

\section{Data Analysis}

In the following section, we will try to explain the patent intensity (patents per capita times 1000) with the help of regressions. Regressions appear to be the most suitable statistical method in the context of this research. On the one hand, they are demanding enough to include multiple dimensions of influence, and on the other, regressions are still sufficiently comprehensible to provide insights beyond specialized level of expertise. The beta values will be depicted since they reflect the relative strength of the variables of influence. In addition, the significances are named, ${ }^{* * *}$ stands for $<0.01,{ }^{* *}$ for $<0.05,{ }^{*}$ for $<0.1$ error probability. The dependent variable patent intensity describes patent applications in relation to population in order to neutralize effects based on differences in the sizes of population in regions.

The effects of diversity on innovation performance will be analyzed at two different spatial levels. First, we will run regressions for the level of 402 districts and cities. Second, the regional level of 96 planning regions will be analyzed. In Table 1, we show four different models. The common base model includes only structural elements. These structural core elements relate to the existence of industry on the one hand and the regional structure on the other. Since it is common knowledge that the industry is relatively patent intensive (Rammer \& Pesau, 2011), we control for 
an overestimation of patents in regions with a high level of industrial production by including a key indicator, i.e. the share of regular employees subject to social security within the industry. We also control for population density, since patent activities are more likely to occur in urban than in rural areas (e.g., Audretsch 1998). Nonetheless, this indicator is not easy to interpret as the most densely populated regions are not necessarily the strongest research regions. District and municipal boundaries have been defined historically and confined administratively and big cities with a similar population sometimes cover more and sometimes less land. In addition, more sparsely populated areas may be located in the outskirts of agglomeration centers, but can still have influence via commuters. We also worked with an additional, non-linear, version of the population density, which however was rarely significant. Overall, the variable of population density has proven to have the strongest effect towards alternatives such as urban-rural-dummies and similar other ones.

At first, we also worked with a second regional indicator, a dummy, which differentiated western and eastern areas. The reasoning for this was that regions in the new federal states experienced a strong de-industrialization process after the unification and the remaining parts rather fulfilled the function of an extended workbench instead of a research department. However, this dummy proved problematic, as especially in the milieu information, some groups (middle-class center, precarious milieu) are very much concentrated in the new federal states. Moreover, we found high levels of multicollinearity ${ }^{2}$ for this variable and thus decided to exclude it from our calculations. The renunciation of the west-east dummy does not cause any real loss of information and in our final model, the $\mathrm{R}^{2}$ in fact even increased slightly after leaving it out. For our best model, we have also calculated a model that only includes West-German regions (including the mixed Berlin).

The very detailed district level can be expected to exhibit neighborhood- and spillover effects, i.e. the research intensity of adjacent areas has an impact on our own research (Eckey, 2007). This phenomenon has been analyzed through the computation of patent citations; one of the results was that patents are cited more often in close proximity to the region where they are created (Jaffe et al., 1992). Since we did not have any information on patent citations available, we used a different method to consider these spillover-effects. We constructed a matrix of all the districts $(402 \times 402)$, and calculated the respective mean for each distance. Based on the assumption that distant patent activities were less important than closer ones, different versions of spillover-effects were tested: (all added up) patents divided by distance, patents divided by the square of the distance, proximate patents (up to 100 or $200 \mathrm{~km}$ versus others as a dummy). The result showed that the sum of the

2 As so often with regionally oriented studies, a significant statistical link between sizes exists. Therefore, multicollinearity must be taken into consideration when regressions are used. If VIF-sizes (Variance Inflation Factor) are too high, the variable needs to be dispensed. 
patents divided by distance had the highest impact. Therefore, only this measure will be applied in the following section. Whether this measure was then divided by population numbers or not, did not affect the results, we thus used absolute values.

We have operationalized the potential influence of diversity through the proportion of foreigners as a share of all employees obligated to social security. At first glance, this solution appears to be overly simplistic, since the measurement of cultural diversity usually involves an index that is created according to the Herfindahlmethod: the sum of the square of all nationalities divided by the square of all people. Due to the lack of availability of appropriate data ${ }^{3}$, that is detailed information as to how many employees had which citizenship, we resorted to this indicator. Significant effects of cultural diversity on regional patent activities could also be demonstrated by Grözinger (2015) who used data from the 2004/2005 IAB regional sample to calculate a Herfindahl index.

A correlation between the Herfindahl index and the indicator we apply here, the share of foreigners amongst all employees subject to social security, results in a value of $0.91^{* * *}$. The strong correlation confirms that using the proportion of foreigners as a proxy for diversity by country of origin represents a well-secured alternative solution (see also Dohse \& Gold, 2015).

In Table 2 we have included possible age effects on the basis of the extended standard model - industry rate, population density, neighboring patents. The share of 30-50 aged (the "Middle Generation") employees is added as an explanatory variable.

\section{Findings}

\section{Patents and District Level}

Our first model (D1 - where the D stands for districts) is used as a base model including the industrial rate (the share of social insurance obligated employees in the industry against all social insurance obligated employees) and population density (inhabitants per square kilometer). The model is rather weak, since it explains only $13 \%$ of variance.

Model D2 shows the result improvement by incorporating the neighborhood effect: an increase in $\mathrm{R}^{2}$ of 0.129 to 0.250 . And the effect of this variable is larger than either of the two structural control variables

The D3 model incorporates the first 'real' explanation attempt beyond the environmental variables. It includes the above stated assumption that a higher level of human capital is decisive for innovation and includes - in addition to the aforemen-

3 The so-called regional sample of the IAB currently still ends with 2004 and was therefore too outdated for the purpose of our study (http://fdz.iab.de/de/FDZ_Individual_Data/ IAB_Employment_Samples.aspx). 
tioned variables - highly qualified personnel (the proportion of employees with a higher education degree or similar qualification). This variable increases the $\mathrm{R}^{2}$ to 0.325 , a first optimum value. Moreover, the share of foreigners in model D4 exhibits a significant effect, although slightly weaker than that of high-skilled workers. Unlike one might expect this is not a result of the fact that employees with foreign citizenship tend to work in low-skilled industry-jobs relatively often. The correlation between the share of workers in the industry and foreign workers is low with 0.115 .

\begin{tabular}{|l|l|l|l|l|}
\hline & Model D1 & Model D2 & Model D3 & Model D4 \\
\hline Industrial quota & $\mathbf{0 , 2 5 8 ^ { * * * }}$ & $\mathbf{0 , 2 4 0 ^ { * * * }}$ & $\mathbf{0 , 2 3 0 ^ { * * * }}$ & $0,203^{* * *}$ \\
\hline Population density & $\mathbf{0 , 2 6 3 ^ { * * * }}$ & $\mathbf{0 , 1 8 6 ^ { * * * }}$ & $-\mathbf{0 , 0 1 0}$ & $0,077^{*}$ \\
\hline Neighborhood patent & - & $\mathbf{0 , 3 5 9 ^ { * * * }}$ & $\mathbf{0 , 2 8 6 ^ { * * * }}$ & $0,253^{* *}$ \\
\hline Highly qualified & - & - & $\mathbf{0 , 3 5 5 ^ { * * * }}$ & - \\
\hline $\begin{array}{l}\text { Proportion of foreign } \\
\text { employees }\end{array}$ & - & - & - & $0,337^{* * *}$ \\
\hline $\mathrm{R}^{2}$ (corr.) & 0,129 & 0,250 & 0,325 & 0,333 \\
\hline
\end{tabular}

Table 1: Patent activity at district level I

In model $\mathrm{D} 5$ we see a positive correlation of the age variable, but only with a very moderate increase of $\mathrm{R}^{2}$ (model D5 in comparison to model D2).

Now, one can argue - as in the case of nationality - that it is not the proportion of an age group that is relevant but the mix of ages. In the INKAR CD provided subdivisions - under 20, 20-25, 25-30, 30-50, 50-60, 60-65, 65 - of the obligated social insured employees, once again an indicator for age diversity was created and tested in accordance the Herfindahl-method. In model D6 only a minimal significance for it arises, and the impact on the $\mathrm{R}^{2}$ is very low.

Now, when combining all the individually tested variables in one single model, we observe a considerably high level of multicollinearity. In particular, the age diversity and the proportion of 30-50 aged correlate to a very high degree. A comprehensive model, including high-skilled foreigners, 30-50 aged and age diversity, leads to nontolerable VIF values for the latter two variables. 


\begin{tabular}{|l|l|l|l|}
\hline & Model D5 & Model D6 & Model D7 \\
\hline Industrial quota & $\mathbf{0 , 2 3 6 ^ { * * * }}$ & $\mathbf{0 , 2 4 3 ^ { * * * }}$ & $0,193^{* * *}$ \\
\hline Population density & $\mathbf{0 , 1 3 4 ^ { * * * }}$ & $\mathbf{0 , 1 6 3 ^ { * * * }}$ & $-0,125^{* *}$ \\
\hline Neighborhood patent & $\mathbf{0 , 3 1 7 ^ { * * * }}$ & $\mathbf{0 , 3 4 5 ^ { * * * }}$ & $0,176^{* * *}$ \\
\hline Highly qualified & - & - & $0,363^{* * *}$ \\
\hline $\begin{array}{l}\text { Proportion of foreign } \\
\text { employees }\end{array}$ & - & - & $0,344^{* * *}$ \\
\hline $\begin{array}{l}\text { Proportion of 30-50 } \\
\text { year olds }\end{array}$ & $\mathbf{0 , 1 8 6 ^ { * * * }}$ & - & - \\
\hline Age diversity & - & $0,089^{*}$ & - \\
\hline $\mathrm{R}^{2}$ (corr.) & 0,278 & 0,255 & 0,412 \\
\hline
\end{tabular}

Table 2: Patent activity at district level II

The inclusion of only one of the two age variables lowers these values, but the effects have no more significance in either of the two variations.

Consequently, in our model D7 - adding to the control variables, only the two measures highly qualified and foreign employees had a significant effect. Both combine and lead to a further increase of $\mathrm{R}^{2}$ to 0.412 . The education component has the strongest influence, and the proportion of foreigners is almost equally strong. The population density changes the algebraic sign, i.e., qualification and diversity dominate occurrences much more than the settlement structure. The industry rate and neighboring patents retain their highly significant positive explanation proportion.

As an alternative to these somewhat more established approaches, additionally attempts were made to explain patent intensity by the composition of social milieus. However, once again one is faced with the problem of relatively high multicollinearity.

Some of the milieus correlate with each other to a fairly high degree. For instance, it can be demonstrated that the New Middle Class and the Precarious milieus are both strongly represented in the same districts $\left(r>0.9^{* * *}\right)$.

In order to avoid internal correlations, we decided to condense the ten milieus into larger groups. We then identified one group which consists of four individual milieus that have a strong correlation with the relative patent activity. These are the Established-Conservative, the Liberal-intellectual, the High Achiever and the Movers and Shakers milieu. These four groups were combined into an indicator of innovation affine milieus. Its share ranges from just over 19\% (Altenburger district) to $44 \%$ (Munich).

The assumptions we made in part 2.4.2 about the localization of innovative milieus - rather in the right and the top in Figure 1 - can only partially be confirmed. It is likely that complementarities become visible here: Innovation processes within 
firms are complex processes and involve multiple actors. Thus, in our example it is not only the expeditionary researcher, but also the conservative firm-owner and the liberal managing head of department who are involved in the innovation processes.

\begin{tabular}{|l|l|l|l|}
\hline & Model D8 & Model D9 & Model D10 (W) \\
\hline Industrial quote & $\mathbf{0 , 2 0 8 ^ { * * * }}$ & $\mathbf{0 , 1 9 1 ^ { * * * }}$ & $0,189^{* * *}$ \\
\hline Population density & $\mathbf{0 , 1 2 7 ^ { * * * }}$ & $\mathbf{- 0 , 0 8 7 ^ { * }}$ & $-0,097$ \\
\hline Neighborhood patent & $\mathbf{0 , 2 3 3 ^ { * * * }}$ & $\mathbf{0 , 1 5 3 ^ { * * * }}$ & $0,142^{* * *}$ \\
\hline Highly qualified & - & $\mathbf{0 , 3 2 2 ^ { * * * }}$ & $0,359^{* * *}$ \\
\hline $\begin{array}{l}\text { Proportion of foreign } \\
\text { employees }\end{array}$ & - & $\mathbf{0 , 1 7 3 ^ { * * * }}$ & $0,138^{* * *}$ \\
\hline $\begin{array}{l}\text { Innovation affine Mi- } \\
\text { lieus }\end{array}$ & $\mathbf{0 , 3 9 5 ^ { * * * }}$ & $\mathbf{0 , 2 6 6 ^ { * * * }}$ & $0,209^{* * *}$ \\
\hline $\mathrm{R}^{2}$ (corr.) & 0,382 & 0,449 & 0,432 \\
\hline
\end{tabular}

Table 3: Patent activity at district level III

Model D8 in Table 3 shows the first result. The $\mathrm{R}^{2}$ is as comparably high as in the models D3 and D4 and the milieu variable has the highest explanatory power.

The next question that we sought to answer was whether the models D7 and D8 could also be combined or whether they describe the same phenomenon from different perspectives. The new model D9 shows this attempt and represents our final model.

The merging of both models results in a further increase of the explanatory power to $\mathrm{R}^{2}=0.449$ without encountering multicollinearity. Industrial quota and neighbor patents continue to play a role in the explanation of patent activity.

Only the variable 'population density' loses almost all significance, since the population composition of milieus and diversity now largely account for the influence of urbanity. Overall, the education variable has the greatest impact, followed by the milieu variable and the proportion of foreign workers. Finally, model D10 repeats the last calculation, but is limited to the western district $(\mathrm{N}=326)$ in order to check again that due to the omission of the east-west differences no explanatory imbalance is created. Yet, the direction of the effect and significances of the central variables are all preserved.

\section{Patents and Regional Planning Level}

Does this result still hold even when aggregated to the next higher level? As described above, planning regions are often considered particularly suitable for regional analyses. One can expect that the influence of neighboring patents becomes less obvious, as the neighborhood now extends much further. 
In Table 4, analogous to Table 1 at the district level the discovered results for space planning can be found. Model P1 - P stands for planning regions- shows significance for the industry rate and population density, model P2 for neighbor patents complements almost exclusively only for this new variable.

\begin{tabular}{|l|l|l|l|l|}
\hline & Model P1 & Model P2 & Model P3 & Model P4 \\
\hline Industrial quote & $\mathbf{0 , 4 2 2 ^ { * * * }}$ & $\mathbf{0 , 2 0 6 ^ { * }}$ & $\mathbf{0 , 2 9 2 ^ { * * * }}$ & $0,182^{*}$ \\
\hline Population density & $\mathbf{0 , 1 8 1 ^ { * }}$ & $\mathbf{0 , 1 2 4}$ & $-\mathbf{0 , 0 5 5}$ & $-0,016$ \\
\hline Neighborhood patent & - & $\mathbf{0 , 4 0 0 ^ { * * * }}$ & $\mathbf{0 , 3 3 6 ^ { * * * }}$ & $-0,124$ \\
\hline Highly qualified & - & - & $\mathbf{0 , 4 5 3 ^ { * * * }}$ & - \\
\hline $\begin{array}{l}\text { Proportion of foreign } \\
\text { employees }\end{array}$ & - & - & - & $0,711^{* * *}$ \\
\hline R2 (corr.) & 0,158 & 0,269 & 0,427 & 0,523 \\
\hline
\end{tabular}

Table 4: Patent activity at spatial planning level I

The economics of education model P3 leads to a significant increase in the explanatory power of $\mathrm{R}^{2}$ of 0.427 , which is the highest value found so far. Model P4 can again increase this slightly through the alternative introduction of the proportion of foreign workers.

In Table 5, the age variables are reintroduced (models P5 and P6). At least this time, the proportion of 30-50 years olds is significantly positive; however the age diversity variable is even weaker. Similar to the level of the districts, they correlate very strongly and do not explain anything more if one of the other variables is added to one of these two. Model P7 finally combines the clearly impacting sizes highly qualified and the proportion of foreign employees. The resulting $\mathrm{R}^{2}$ is the highest so far. In contrast to D7, the proportion of foreign-time employees is now the relative stronger one, however both remain highly significant positive and with the highest potency.

Of the control variables, the industrial quota is within the same league, consistently positive. 


\begin{tabular}{|l|l|l|l|}
\hline & Model P5 & Model P6 & Model P7 \\
\hline Industrial quota & $\mathbf{0 , 2 5 1 ^ { * * }}$ & $\mathbf{0 , 2 7 2 ^ { * * }}$ & $0,229^{* * *}$ \\
\hline Population density & $-\mathbf{0 , 0 0 2}$ & $\mathbf{0 , 0 4 6}$ & $-0,210^{* * *}$ \\
\hline Neighborhood patent & $\mathbf{0 , 3 1 3 ^ { * * * }}$ & $\mathbf{0 , 3 6 1 ^ { * * * }}$ & 0,005 \\
\hline Highly qualified & - & - & $0,318^{* * *}$ \\
\hline $\begin{array}{l}\text { Proportion of foreign } \\
\text { employees }\end{array}$ & - & - & $0,599^{* * *}$ \\
\hline $\begin{array}{l}\text { Proportion of 30-50 } \\
\text { years olds }\end{array}$ & $\mathbf{0 , 2 7 3 ^ { * * }}$ & - & - \\
\hline Age diversity & - & $\mathbf{0 , 1 8 7 ^ { * }}$ & - \\
\hline R2 (corr.) & 0,313 & 0,285 & 0,594 \\
\hline
\end{tabular}

Table 5: Patent activity at spatial planning level II

The regional planning level exhibits strong internal relationships: especially New Middle class and precarious milieu repeatedly correlate with each other. But also other relationships are relatively will be depicted strong and result in non-tolerable VIF values if included in a simple regression model.

Therefore, we proceeded the same way as we did on the smaller geographical scale, by creating an indicator for the innovation affine milieus on the basis of those milieus that strongly correlate with patents: the Established-Conservative, the Liberalintellectual, the High Achiever and the Movers and Shakers milieu.

\begin{tabular}{|l|l|l|l|}
\hline & Model P8 & Model P09 & Model P10 (W) \\
\hline Industrial quote & $\mathbf{0 , 0 9 4}$ & $\mathbf{0 , 2 0 2 ^ { * * * }}$ & $0,225^{* *}$ \\
\hline Population density & $-\mathbf{0 , 0 3 6}$ & $\mathbf{- 0 , 2 0 2 ^ { * * * }}$ & $-0,225^{* *}$ \\
\hline $\begin{array}{l}\text { Neighborhood } \\
\text { patent }\end{array}$ & $\mathbf{0 , 2 1 1 ^ { * * }}$ & - & - \\
\hline Highly qualified & - & $\mathbf{0 , 3 3 0 ^ { * * * }}$ & $0,336^{* *}$ \\
\hline $\begin{array}{l}\text { Proportion of foreign } \\
\text { employees }\end{array}$ & - & $\mathbf{0 , 4 0 2 ^ { * * * }}$ & $0,343^{* * *}$ \\
\hline $\begin{array}{l}\text { Innovation affine Mi- } \\
\text { lieus }\end{array}$ & $\mathbf{0 , 5 3 8 ^ { * * * }}$ & $\mathbf{0 , 2 6 6 ^ { * * }}$ & $0,233^{* *}$ \\
\hline R2 (corr.) & $\mathbf{0 , 4 7 0}$ & $\mathbf{0 , 6 2 3}$ & 0,603 \\
\hline
\end{tabular}

Table 6: Patent activity at spatial planning level III

Even the simpler model P8 in Table 6 with an $\mathrm{R}^{2}$ of 0.470 shows a significantly better explanatory power than the comparable D8, and the affine innovation milieus explain this result to a large extent.

This value increases even more after the other explanation approaches are integrated in model P9. However, the VIF value for the foreign workers now lies slightly above 4. As some sources in the literature declare VIF values above 4 to be problematic, 
the non-significant neighbor patents variable was omitted resulting in all remaining VIF values to stay below 4. Thus, P9 is the best overall model with an $\mathrm{R}^{2}$ of 0.623 . The proportion of foreign workers exhibits the strongest effect, followed by the qualification dimension, and finally the milieus. Following the conventional practice, the latter is marked at the level of a $5 \%$ - error probability with ${ }^{* *}$, the precise value, however, lies at $1.1 \%$ and thus very close to the ${ }^{* * *}$. Finally, the last model (R10) was calculated for West German regions only. Since only 75 planning regions remain, the significances decrease slightly, but the basic explanatory-correlations as well as a still relatively high $\mathrm{R}^{2}$ of 0.603 persist.

\section{Discussion}

Due to the regressions, it is relatively clear that only the examined age variables do not have any significant effect. In contrast, all three additional operationalized approaches - highly qualified, foreigner's proportion, innovation affine milieus - add to the explanation of patent intensity. The relative weight of these dimensions, however, depends on the level of analysis. Cultural diversity has a positive effect even when qualifications are controlled for; therefore, we can assume that it is not only highly skilled immigration that is beneficial for patent activities, but also immigration of different skill levels. In addition, we find that the correlation between the highly qualified personnel and the innovative milieu is weak; therefore both variables must exert an independent effect.

We can also show relatively precisely that the planning regions offer a greater explanatory value than the administrative districts. In the literature, planning regions have been discussed as a particularly suitable level of analysis for comprehensive regional studies. Our calculations confirmed this assumption.

Finally, the existence of reverse causality is always possible when using regressions. One critical objection is that it is not the high proportions of high qualified, the foreigners, or the existence of innovation affine milieus promoting patent intensity, but that instead areas with relatively high patent activity attract these groups. This objection is less frequent in regards to highly qualified and innovation-affine milieus, since the direction of the effect is quiet easily derived from theoretical assumptions. However, the direction of the effect for cultural diversity is less obvious.

\begin{tabular}{|l|l|l|l|l|}
\hline \multicolumn{5}{|c|}{ Correlation with the proportion of foreign employees } \\
\hline & \multicolumn{1}{|c|}{ District } & $\begin{array}{c}\text { District } \\
\text { West }\end{array}$ & Planning region & $\begin{array}{c}\text { Planning region } \\
\text { West }\end{array}$ \\
\hline Unemployment & $-\mathbf{0 , 4 5 8 ^ { * * * }}$ & $-\mathbf{0 , 0 8 1}$ & $-\mathbf{0 , 5 9 3 ^ { * * * }}$ & $-0,159$ \\
\hline GDP/ capita & $0,396^{* * *}$ & $0,289^{* * *}$ & $0,725^{* * *}$ & $0,562^{* * *}$ \\
\hline
\end{tabular}

Table 7: Correlation of the proportion of foreigners 
We do not have an accurate test for this, since a long-term observation including repeated measurements is not available. What we do have is a plausibility consideration. Since regional patent intensity is usually neither known to nor a fixed attractor for employees, reasons must be looked for as to why people - such as the case with people with non-German nationality - move to a specific area. Economically, there are two reasons of paramount importance: the availability of jobs and the level of income. We have operationalized these two factors with the unemployment rate and the GDP / capita. The latter quantity is probably the less meaningful as the cost of living, especially for tenants, is likely to be higher in these regions (GDP / capita and population density also highly correlated).

Table 7 shows the correlations of the proportion of foreign workers with these two variables, at district level and on regional planning level. In both cases, we find the expected relationship, one time negative, and one time positive. Moreover, the values are highly significant, with medium to high values. However, a relatively high income and low unemployment risk especially characterize the West, less the East. Furthermore, one finds relatively few non-Germans in the regions of the new federal states for a number of reasons. If one limits the area of study, in order to eliminate this east-west interference effect, only to the western part of the country, the correlation coefficient decreases and the significance of the unemployment rate disappears. Thus, we conclude that these factors do not influence the share of foreign population in our analysis and that we can exclude reverse causality.

\section{Conclusion and Future Lines of Research}

We have linked various, normally separate, discourses: how does human capital, how cultural diversity, how age, how milieu membership affect regional innovation activity, as measured by patents?

Of our 5 tested hypotheses, only one proved to be false, namely our prediction that a low level of age diversity and a high proportion of inhabitants over 50 years old is negatively correlated with patent output. All the other hypotheses outlined in section 2.6 were confirmed.

To sum up our results, we can say that the three dimensions - qualification, cultural diversity and milieu affiliation- all contribute to an explanation of innovation activities on the regional level and that it is possible to combine them.

Secondly, the proportion of the explained regional variance is already high. Our best model, reaches a $\mathrm{R}^{2}$ of above 0.6 .

Thirdly, the following lessons can be drawn at the policy-level: the promotion of education, especially at the university level, openness to cultural diversity, and addressing the needs of the innovation affine milieus are important mechanisms for the enhancement of regional innovation capacities. 
Fourthly, we found only small effects for the age variable on innovation activity. This is most likely related to the currently low level of regional variance, but may change in the future. We assume that other dimensions such as education, diversity, and a favorable composition of social milieus strongly compensate for the influence of this dimension at the moment.

Our paper is limited in several ways. We showed that a larger spatial layout (planning regions as opposed to administrative districts) has proved to be more useful for calculating the different diversity effects. But we did not test our models at the regional level of labor market regions which could reflect economic linkages better that planning regions do. For further studies, it would be interesting to see if the spatial layout of labor market regions improves the explanatory strength of our innovation models.

As regards the effects of cultural diversity on patent activities, we focus on macroeconomic outcome variables and neglect the underlying mechanisms of cultural diversity. This is partly due to the lack of adequate data. Using the regional share of foreigners as a proxy for cultural diversity, the data does not allow for a more detailed analysis of the mechanisms at work. The same applies to the concept of social milieus. In both cases, we cannot test our theoretical assumptions about how the variables influence the innovation capability of individuals with the data we collected in the context of this study. Further research is required to elucidate the underlying mechanisms that lead to the effects we have demonstrated in this paper.

\section{References}

Acs, Z. J., Anselin, L., \& Varga, A. (2002). Patents and innovation counts as measures of regional production of new knowledge. Research Policy, 31(7), 1069-1085.

Alesina, A., \& La Ferrara, E. (2005). Ethnic diversity and economic performance. Journal of Economic Literature, 43(3), 762-800.

Arnold, M., Mattes, A., \& Sandner, P. (2014). Regionale Innovationssysteme im Vergleich. DIW Wochenbericht, 81(5), 79-87.

Arntz, M., \& Gregory, T. (2014). What old stagers could teach us - examining age complementarities in regional innovation systems (ZEW Discussion Paper No. 14-050) Mannheim: Zentrum für europäische Wirtschaftsforschung (ZEW). Retrieved from https://papers.ssrn.com/sol3/ papers.cfm?abstract_id=2475947

Audretsch, D. B. (1998). Agglomeration and the location of innovative activity. Oxford Review of Economic Policy, 14(2), 18-29.

Audretsch, D. B., Dohse, D., \& Niebuhr, A. (2010). Cultural diversity and entrepreneurship: A regional analysis for Germany. Annals of Regional Science, 45(1), 55-85. doi:10.1007/ s00168-009-0291-x

Baltes, P. B, \& Staudinger U. M. (2000). Wisdom. A metaheuristic (pragmatic) to orchestrate mind and virtue toward excellence. American Psychologist, 55(1), 122-136.

Barnett, H. G. (1953). Innovation: The basis of cultural change. New York, NY: McGraw Hill. 
Barth, B., \& Flaig, B. B. (2012). Was sind Sinus-Milieus'? In P. M. Thomas (Ed.), Jugendliche Lebenswelten. Perspektiven für Politik, Pädagogik und Gesellschaft (pp. 11-35). Heidelberg: Spektrum Akademischer Verlag.

Bathelt, H., \& Glückler, J. (2012). Wirtschaftsgeographie. Ökonomische Beziehungen in räumlicher Perspektive. Stuttgart: UTB.

Bellini, E., Ottaviano, G. I., Pinelli, D., \& Prarolo, G. (2013). Cultural diversity and economic performance: evidence from European regions. In R. Crescenzi, \& M. Percoco (Ed.), Geography, institutions and regional economic performance (pp. 121-141). Berlin, Heidelberg: Springer.

Bellmann, L., Crimmann, A., Evers, K., \& Hujer, R. (2013). Regional determinants of establishments' innovation activities: A multi-level approach (Discussion Paper Series, 7572). Bonn: Forschungsinstitut zur Zukunft der Arbeit (IZA).

Beteille, A. (1977). Inequality among Men. Oxford: Blackwell.

Bosetti, V., Verdolini, E., \& Cattaneo C. (2012). Ethnic heterogeneity and knowledge formation in Europe. Review of Environment, Energy and Economics (Re3). Retrieved from: http:// re3.feem.it/getpage.aspx?id=5148

Brenner, T.; Broekel, T. (2011): Methodological issues in measuring innovation performance of spatial units. In: Industry and Innovation, 18(1), 7-37.

Budde, R., \& Eilers, L. (2014). Sozioökonomische Daten auf Rasterebene. Datenbeschreibung der microm-Rasterdaten (RWI Materialien, 77). Essen: Rheinisch-Westfälisches Institut für Wirtschaftsforschung. Retrieved from: https://www.econstor.eu/bitstream/ 10419/97627/1/787947717.pdf

Christaller, W. (1980). Die zentralen Orte in Süddeutschland. Eine ökonomisch-geographische Untersuchung über die Gesetzmässigkeit der Verbreitung und Entwicklung der Siedlungen mit städtischen Funktionen. Darmstadt: Wissenschaftliche Buchgesellschaft. (Original work published 1933)

Cooke, P. (2001). Regional innovation systems, clusters, and the knowledge economy. Industrial and Corporate Change, 10(4), 945-974.

Diaz-Bone, R. (2003). Milieumodelle und Milieuinstrumente in der Marktforschung. Sozialwissenschaften und Berufspraxis, 26(4), 365-380.

Didero, M., Gareis, K., Marques, P., \& Ratzke, M. (2008). Differences in innovation culture across Europe. Retrieved from: https://pdfs.semanticscholar.org/ 84f8/3279282705e1341546a83b3d564c62565b2 a.pdf

Dohse, D., \& Gold, R. (2015). Determining the impact of cultural diversity on regional economies in Europe (WWW for Europe Working Paper, 58). Kiel: IfW. Retrieved from: https://www.econstor.eu/bitstream/10419/125710/1/WWWforEurope_WPS_no058_MS101.pdf.

Eckey, H.-F., Kosfeld, R., \& Türck, M. (2007). Regionale Entwicklung mit und ohne räumliche Spillover-Effekte. Jahrbuch für Regionalwissenschaften, 27(1), 23-42.

Etzkowitz, H., \& Leydesdorff, L. (2000): The dynamics of innovation: from national systems and "Mode 2" to a triple helix of university - industry - government relations. Research Policy, 29, 109-123.

Florida, R. L. (2004). The rise of the creative class. And how it's transforming work, leisure, community and everyday life. New York, NY: Basic Books.

Florida, R. L. (2008). Who's your city? How the creative economy is making where to live the most important decision of your life. New York, NY: Basic Books. 
Franke, R. H., Hofstede, G., \& Bond, M. H. (1991), Cultural roots of economic performance: A research note. Strategic Management Journal, 12(S1), 165-173.

Freeman, C. (1987). Technology policy and economic performance. London: Pinter.

Fujita, M., \& Krugman, P. (1995): When is the economy monocentric? Regional Science and Urban Economics, 25(4), 505-528.

Fujita, M., Krugman, P., \& Mori, T. (1999). On the evolution of hierarchical urban systems. European Economic Review, 43(2), 209-251.

Fujita, M., Krugman, P., \& Venables, A. (2001) The spatial economy. Cities, regions and international trade ( $1^{\text {st }}$ ed.). Cambridge, MA: MIT Press.

Gregory, T., \& Patuelli, R. (2013). Regional age structure, human capital and innovation - Is demographic ageing increasing regional disparities? (ZEW Discussion Paper No. 13-057). Mannheim: Zentrum für europäische Wirtschaftsforschung (ZEW). Retrieved from: https:// www.econstor.eu/bitstream/10419/80424/1/766279448.pdf

Griliches, Z. (1990). Patent statistics as economic indicators: A survey. Journal of Economic Literature, 28(4), 1661-1701.

Grözinger, G. (2015). Diversity, creative milieu, innovation. Results of a regional analysis for Germany. In C. Gaitanides, \& G. Grözinger (Eds.), Diversity in Europe (pp. 95-107). Baden Baden: Nomos-Verlag.

Grözinger, G., \& Matiaske, W. (Eds.) (2005). Deutschland regional: Sozialwissenschaftliche Daten im Forschungsverbund. München: Hampp.

Harrison, L. E., \& Huntington, S. (2000). Culture matters. How values shape human progress. New York, NY: Basic Books.

Herbig, P. A., \& Miller, J. C. (1993). Culture and technology. Journal of Global Marketing, 6(3), 23-45.

Hofstede G. H. (1980). Culture's consequences: Comparing values, behaviors, institutions and organizations across nations. London: Sage Publications.

Hotelling, H. (1929). Stability in competition. Economic Journal, 39(153), 41-57.

Hradil, S. (2006). Soziale Milieus. Eine praxisorientierte Forschungsperspektive. In K. Belwe (Ed.), Soziale Milieus. Aus Politik und Zeitgeschichte - Beilage zur Wochenzeitung „Das Parlament"(pp. 3-10). Frankfurt am Main: Bundeszentrale für Politische Bildung.

Hunt, J., \& Gauthier-Loiselle, M. (2009). How much does immigration boost innovation? (Discussion Paper Series, 3921). Bonn: Institute for the Study of Labor. Retrieved from: https:// www.econstor.eu/bitstream/10419/35709/1/589802992.pdf

Hunt, J. (2011). Which immigrants are most innovative and entrepreneurial? Distinctions by entry visa. Journal of Labor Economics 29(3), 417-457.

Isard, W., \& Liossatos, P. (1979). Spatial dynamics and optimal space-time development. New York, NY: North-Holland.

Jaffe, A. B., Trajtenberg, M., \& Henderson, R. (1992). Geographic localization of knowledge spillovers as evidenced by patent citations. Quaterly Journal of Economics, 108(3), 577-598.

Karlsson, C. (Ed.) (2008): Handbook of research on cluster theory. Cheltenham, UK: Edward Elgar.

Kerr, W. R., \& Lincoln, W. F. (2010). The supply side of innovation: H-1B visa reforms and US ethnic invention. Journal of Labor Economics, 28(3), 473-508. 
Kirkman, B. L., Lowe K. B., \& Gibson, C. B. (2006). A quarter century of culture's consequences: A review of empirical research incorporating Hofstede's cultural values framework. Journal of International Business Studies, 37(3), 285-320.

Kosfeld, R., \& Werner, A. (2012). Deutsche Arbeitsmarktregionen - Neuabgrenzung nach den Kreisgebietsreformen 2007-2011. Raumforschung und Raumordnung, 70(1), 49-64.

Krugman, P. R. (1997): Development, geography, and economic theory. Cambridge, MA: MIT Press. Landes, D. (1998). The wealth and poverty of nations. New York, NY: Norton.

Lee, C. (1998). Determinants of national innovativeness and international market segments. International Marketing Review, 7(5), 39-49.

Lösch, A. (1940). Die räumliche Ordnung der Wirtschaft. Eine Untersuchung über Standort, Wirtschaftsgebiete und internationalem Handel. Jena: Fischer.

Lucas, R. E. (1988). On the mechanics of economic development. Journal of Monetary Economics, 22(1), 3-42.

Mankiw, N. G., Romer, D., \& Weil D. N. (1992). A contribution to the economics of economic growth. Quarterly Journal of Economics, 107(2), 407-437.

Marshall, A. (2009). Principles of economics. London: Macmillan. Original work published 1890.

Miggelbrink, J. (2002). Der gezähmte Blick. Zum Wandel des Diskurses über „Raum “ und „Region" in humangeographischen Forschungsansätzen des ausgehenden 20. Jahrhunderts (Beiträge zur regionalen Geographie, 55). Leipzig: Institut für Länderkunde.

Mokyr, J. (1991). The lever of riches: Technological creativity and economic progress. London: Oxford University Press.

Niebuhr, A. (2006). Migration and innovation: Does cultural diversity matter for regional R\&D activity? (IAB Discussion Paper Nr. 14/2006). Nürnberg: Institut für Arbeitsmarkt- und Berufsforschung (IAB). Retrieved from: https://www.econstor.eu/bitstream/ 10419/31908/1/518522741.PDF

Ohlin, B. G. (1933). Interregional and international trade. Cambridge: Harvard University Press.

Ottaviano, G. I. P., \& Peri, G. (2006). The economic value of cultural diversity: Evidence from US cities. Journal of Economic Geography, 6(1), 9-44.

Porter, M. E. (1998). The competitive advantage of nations. Basingstoke: Macmillan.

Rammer, C., \& Pesau, A. (2011). Innovationsverhalten der Unternehmen in Deutschland 2009. Aktuelle Entwicklungen und ein internationaler Vergleich (Studien zum Deutschen Innovationssystem Nr.7-2011). Mannheim: Zentrum für Europäische Wirtschaftsforschung (ZEW). Retrieved from: http://e-fi.de/fileadmin/Studien/StuDIS_2011/StuDIS_7_2011_01.pdf

Rehfeld, D., \& Terstriep, J. (2013). Regionale Innovationssysteme: 20 Jahre "Regional Innovation System Studies” (Forschung aktuell No.11/2013), Gelsenkirchen: Institut Arbeit und Technik (IAT).

Richter, D., Grözinger, G., \& Langholz, M. (2015). Eine milieubasierte Betrachtung regional verfügbaren Humankapitals. In S. Jeschke, A. Richert, F. Hees, \& C. Jooß (Eds.), Exploring Demographics - Transdisziplinäre Perspektiven zur Innovationsfähigkeit im demografischen Wandel (p. 413-426). Berlin: Springer Verlag.

Romer, P. M. (1990). Endogenous technological change. The Journal of Political Economy, 98(5), 71-102.

Rothwell, R., \& Wissema, H. (1986). Technology, culture, and public policy. Technovation, 4(2), 91-115. 
SINUS Markt- und Sozialforschung GmbH. (2011). Informationen zu den SINUS-Milieus ${ }^{\circledast}$ 2011. Retrieved from: http://www.sinus-institut.de/service/downloadcenter.html

Sinz, M. (2005). Region. Hannover: Akademie für Raumforschung und Landesplanung. Retrieved from: www.arl-net.de/content/handwoerterbuch-der-raumordnung

Skirbekk, V. (2003). Age and individual productivity: A literature survey (MPIDR Working Paper 2003-028). Rostock: Max Planck Institute. Retrieved from: https:/ideas.repec.org/p/dem/ wpaper/wp-2003-028.html

Smith, K. (2005). Measuring innovation. In J. Fagerberg, D. Mowery, \& R. Nelson (Eds.), The Oxford handbook of innovation (pp. 148-177). Oxford: Oxford University Press.

Sociovision. (2009). Die Sinus Milieus. Sinus.

Stuen, E. T., Mobarak, A. M., \& Maskus, K. E (2012). Skilled immigration and innovation: Evidence from enrolment fluctuations in U.S. doctoral programs. The Economic Journal, 122(565), 1143-1176.

Taylor, M. Z., \& Wilson, S. (2012). Does culture still matter? The effects of individualism on national innovation rates. Journal of Business Venturing, 27(2): 234-247.

Von Thünen, J. H. (1826). Der isolierte Staat in Beziehung auf Landwirtschaft und Nationalökonomie oder Untersuchungen über den Einfluß, den die Getreidepreise, der Reichtum des Bodens und die Abgaben auf den Ackerbau ausüben. Hamburg: Perthes.

Ueltzhöffer, J., \& Flaig, B. (1980): Lebensweltanalyse: Explorationen zum Alltagsbewusstsein und Alltagshandeln. Heidelberg: SINUS.

Wadhwa, V., Gereffi, G., Rissing, B., \& Ong, R. (2007). Where the engineers are. Issues in Science and Technology, 23(3), 73-84.

Wieland, T. (2006). Innovationskultur: theoretische und empirische Annäherungen an einen Begriff. Innovationskultur in historischer und ökonomischer Perspektive. Modelle, Indikatoren und regionale Entwicklungslinien. Innsbruck: StudienVerlag.

Weber, A. (1909). Reine Theorie des Standorts. Tübingen: Mohr. 